\title{
How to Stay Healthy While Studying Abroad: Development of an Electronic Magazine for College Students
}

\author{
Hannah M. Lightcap1, Marie Fanelli Kuczmarski'1, Lisa P. Chieffo² \\ ${ }^{1}$ Department of Behavioral Health and Nutrition, University of Delaware, Newark, DE, USA \\ ${ }^{2}$ Institute for Global Studies, University of Delaware, Newark, DE, USA \\ Email:lightcap@udel.edu
}

How to cite this paper: Lightcap, H. M., Kuczmarski, M. F., \& Chieffo, L. P. (2016). How to Stay Healthy While Studying Abroad: Development of an Electronic Magazine for College Students. Creative Education, 7, 2061-2073.

http://dx.doi.org/10.4236/ce.2016.715206

Received: August 8, 2016

Accepted: September 9, 2016

Published: September 13, 2016

Copyright $\odot 2016$ by authors and Scientific Research Publishing Inc.

This work is licensed under the Creative

Commons Attribution International

License (CC BY 4.0).

http://creativecommons.org/licenses/by/4.0/

(c) (i) Open Access

\begin{abstract}
Increasing numbers of US college students are participating in travel study programs. As part of their pre-departure preparation, institutions provide orientation materials covering a range of topics. These materials typically cover such health-related topics as immunizations, sun safety, psychological distress, personal assault, and water quality. However, comprehensive coverage of strategies to ensure optimal physical wellness while traveling has been overlooked. This article describes the development and evaluation of an electronic (e) magazine entitled, "How to Stay Healthy While Studying Abroad". This e-magazine not only explains the importance of physical activity, food and beverage practices, sleep, and stress and time management, but also offers tips for achieving wellness during travel. The primary objective of the study was to evaluate the usefulness of the e-magazine. The secondary objective was to enhance the content of the guide based on an assessment of students' attitudes, perceptions and behaviors related to wellness pre- and post-participation in travel study programs. Prior to travel over $70 \%$ of students felt they would be able to engage in healthful eating and physical activity. Fifty-two percent of students found it challenging to eat healthfully and be physically active on their travel study programs. The vast majority of students (87\%) reported that they found the guide helpful in promoting healthful behaviors. Hydration, health during travel, and getting enough sleep were the top three e-magazine areas utilized. Self-motivation, social support and tips within How to Stay Healthy While Studying Abroad were the top three factors which contributed to achieving physical wellness. The guide was considered useful based on the findings and evidenced by students' recommendations that the guide be shared with all university students.
\end{abstract}

\section{Keywords}

Wellness, Health Behavior, Health Promotion, Travel Study, College Students 


\section{Introduction}

Travel study programs provide an experience unlike any other. Acquiring a global experience is a goal of many college students who recognize that studying abroad may have positive implications for their career paths (Dwyer \& Peters, 2004; Norris \& Gillespie, 2008). Additionally, learning about a new culture and discovering how one adapts to new environments while gaining an understanding of different cultures contributes to students' development of intercultural proficiency (Anderson, Lawton, Rexeisen, \& Hubbard, 2006; Chieffo \& Griffiths, 2004; Clarke, Flaherty, Wright, \& McMillen, 2009; Czerwionka, Artamonova, \& Barbosa, 2015; Douglas \& Jones-Rikkers, 2001; Dwyer \& Peters, 2004; Gambino \& Mohsin Hashim, 2016; Kitsantas, 2004; Stebleton, Soria, \& Cherney, 2013). In this article, travel study programs are defined as both domestic (U.S.-based) and international education programs.

For many students, travel study means leaving a known environment for the first time. Being in a new place may be overwhelming, and adapting to diverse situations may be challenging for some. Most likely, students will encounter fascinating yet different foods, new customs and social atmospheres which could result in culture shock. Culture shock can impact wellness, defined as the dynamic process of becoming aware of, taking responsibility for, and making choices to, strike a balance in behaviors to achieve one's full potential (Corbin \& Pangrazi, 2001; Stewart \& Leggat, 1998). Changes in eating and sleeping habits, loss of interest in activities, and lack of energy are examples of changes in physical wellness due to culture shock associated with travel (JED Foundation \& Settle, 2008).

Research related to wellness among college students who have participated in travel study programs is limited, making it difficult to design targeted prevention education (Hartjes, Baumann, \& Henriques, 2009). Physical wellness not only relates to decisions regarding physical activity, nutrition, and sleep, but also the use of alcohol and other drugs. The travel study destination location can offer new activities and interests that students may not have discovered at home, including new forms of entertainment which may be risky. It is recognized that risk-taking behavior increases in some situations during study abroad (Bonner, 2001). Bonner (2001) reported that the majority of the students she surveyed admitted to alcohol consumption, being intoxicated, and taking part in daredevil activities, often for the first time, during study abroad. Increased alcohol consumption may be due to the fact that most students are of legal age to consume alcohol while outside the US.

Given the increasing medical alerts worldwide such as the Zika virus and dengue fever, it is critical that students should be aware of health issues and practice strategies to achieve optimal health. To prepare students for travel study programs, pre-departure guidance on safety and health is typically provided by faculty who direct these programs and their institutions. "Responsible Study Abroad: Good Practices for Health \& Safety" is a resource providing guidance to institutions, participants, and parents/ guardians from the Interorganizational Task Force on Safety and Responsibility in Study Abroad (2002). In regards to health, pre-departure orientations address a variety 
of topics such as immunizations, psychological distress, personal assault, water quality, and sun exposure. The authors conducted a survey of the top 25 US leading institutions awarding credit for study abroad (Institute of International Education, 2015), and found that none of the pre-departure guidance comprehensively covered all facets of health essential for the achievement of optimal wellness.

A review of the literature reveals $36 \%$ to $54 \%$ of travelers experience physical health problems (Rogers \& Reilly, 2000). At the University of Delaware (UD), students are asked to read a handbook on health and safety abroad as part of their pre-departure preparations for travel study programs. This handbook briefly discusses some physical wellness concepts, such as walking, eating a low-fat diet, trying new foods, being cognizant of what one is eating, discouraging alcohol consumption, and jet lag (Institute for Global Studies Travel Study Handbook, 2015). Yet, UD's Travel Study Handbook content on wellness was not comprehensive, and did not provide targeted messages on ways to achieve optimal wellness or student perspectives on how to stay healthy during travel study programs.

Based on the authors' observations of changes in students' health behavior patterns during a travel study program, it became apparent that students would benefit from a resource that provided practical tips to promote wellness. A comprehensive literature review revealed no previous studies that assessed students' perceptions and attitudes toward achieving wellness while studying abroad. Therefore, only assumptions could be made about how students felt about their health while traveling. Thus, the development of a guide that combined students' points of view on the importance of being healthy during a travel study with specific health tips to promote physical wellness was initiated.

The primary objectives of this study were to evaluate the usefulness of an $e$-magazine entitled, “How to Stay Healthy While Studying Abroad" in promoting physical wellness and to identify barriers to achieve wellness during travel study programs. The secondary objective was to enhance the content of the guide based on an assessment of students' attitudes, perceptions and behaviors related to wellness pre- and post-participation in travel study programs.

\section{Methods}

\subsection{Study Participants}

All students, 18 years of age and older, who were enrolled in a travel study during the 2016 winter session (January term) were eligible to participate in the evaluation of the e-magazine. A total of 1137 students participated in 55 travel study programs sponsored by the University of Delaware. Participants were recruited through an email invite. The study protocol was approved by the University of Delaware's Institutional Review Board.

\subsection{Development of E-Magazine and Pilot Study}

The How to Stay Healthy While Studying Abroad e-magazine was developed from a photographic wellness guide that the authors complied in June 2015. To create this 
photographic guide book, focus groups were conducted with 14 college students during their travel study during the summer of 2015. These students were female, juniors, and enrolled in a health-related major. They visited two European countries and were housed in 4 different locations. The topics discussed during the focus group sessions were components of physical wellness associated with culture shock and published findings related to wellness of college students on travel study programs. They included: physical activity, water and alcohol consumption, attitudes on health topics, major and minor health concerns, and dietary patterns abroad compared to on-campus. In addition, two surveys designed to gather information on lifestyle behaviors were completed on the final day in each country visited.

Focus group discussions revealed that students' major health concerns while studying abroad were weight gain (9 of 14) and increase in alcohol consumption (8 of 14). On the surveys, students were asked to report their general eating habits, physical activity, and alcohol consumption in each country visited, and to compare these to when they were on campus in the United States. The data collected revealed that, while abroad, 13 of the 14 students had an increase in alcohol consumption between 1.5 to 2 times more than their consumption when on campus. Between 9 and 11 students saw an increase in their consumption of fat and carbohydrate dense foods, depending on the country visited. Furthermore, 10 of the 14 students noted a decrease in physical activity while on their study abroad compared to on-campus. These findings echo the assumption that physical activity, eating habits, and alcohol consumption may change according to where someone is in the world and explain why these wellness-related facets were emphasized so heavily in the guide.

Based on the results of the areas of concern from the pilot study, a 22-page printed photographic guide book was developed, providing tips and photographs related to various aspects of physical wellness, such as staying healthy during travel (on a train/plane), time management, dietary habits, snacking, physical activity, quick/convenient fitness, alcohol consumption, hydration, and getting enough sleep. This book was reviewed by 9 students who participated in the pilot study, a random selection of 10 students who engaged in previous travel study programs, and an associate director of UD's Institute for Global Studies. Based on these reviews, the topic of sun safety and student points of view were incorporated into the guide. The aesthetic format of an electronic magazine was chosen since it is a technique accessible to and favored by college students. The final topics addressed in the e-magazine are provided in Table 1. Each section included the rationale documenting the importance of the behavior, practical tips, points of view from college students who had experience on travel study programs, and website resources. The e-magazine was 26 pages long and took approximately 20 - 30 minutes to read.

\subsection{Pre- and Post-Travel Questionnaires}

Qualtrics ${ }^{\oplus}$ survey software (Provo, UT, 2015) was used for both the pre- and post-travel questionnaires. The initial question asked if the respondent was 18 years or older so 
Table 1. Titles of content sections in How to Stay Healthy While Studying Abroad e-magazine.

Why be healthy on your study abroad?

How to stay healthy on the fly.

Sunscreen Use.

Time Management: Work the clock, don't let the clock work you!

Food: New Cuisine.

Physical activity: Make physical activity part of the experience.

Quick Fitness: If you are limited to your room, you CAN make it work for you!

Alcohol: Liquor, wine, and beer, oh dear!

Hydration: A few glasses a day, keeps the dehydration away.

Sleep, sleep, sleep.

Resources: Web links.

parental consent was not needed. Only those students who met this age requirement could proceed. Both questionnaires were tested for understandability and timing with 9 students who previously engaged in travel study. The questionnaires were considered valid based on content validity.

Personal information describing class status, college(s) associated with their major(s), travel study program enrollment, and sex was asked on both questionnaires. Perception of overall health, knowledge of healthful foods, and physical activity were also assessed on both questionnaires. Questions on physical activity were adapted from the physical activity and physical fitness questionnaire from the 2007-08 National Health and Nutrition Examination Survey (2008). Participants were asked to estimate how much water they drank on an average day and how much sleep they got on weekdays (Sunday to Wednesday) and weekends (Thursday to Saturday). Weekends were defined as Thursday to Saturday because of the common on-campus practice of starting one's weekend leisure activities on Thursday night.

The pre-travel questionnaire included a total of 27 questions and took approximately 10 minutes to complete. The format of the questions varied from 5-point Likert scales, ranging from Strongly Disagree to Strongly Agree, for attitudes related to eating and physical activity, to multiple choices to categorize behaviors, and to rank ordering of importance of 10 topics related to physical wellness. Participants were also asked to predict if they thought their alcohol consumption would change. The choices ranged from "Significant decrease in my normal consumption of alcohol (5 drinks less per day)" to "Significant Increase (5 or more drinks per day)". The pre-travel questionnaire was administered approximately 6 weeks prior to departure. Once a student completed the pre-travel questionnaire they were given the link to access the e-magazine. The e-magazine received 192 views.

The post-travel questionnaire mimicked the pre-travel questionnaire in many aspects and had a total of 37 questions. The completion time was approximately 15 minutes. Students were asked to indicate all the topics from the e-magazine they utilized and to identify barriers which prevented them from engaging in healthful behaviors. Participants were also asked if they would be concerned about maintaining their health while on another travel study program. The post-travel questionnaire was available for completion for 3 weeks after the term abroad. 


\subsection{Statistics}

Pre- and post-travel questionnaire responses were tallied and summarized as frequencies. These data were used to determine if any additions, deletions or modifications to the content of the e-magazine were needed. All analyses were performed with SPSS software, release 23. $P$ values were adjusted for multiple comparisons using the Bonferroni test. For all statistical analyses, $P<0.05$ was considered significant.

\section{Results}

\subsection{Demographics of Respondents}

As shown in Table 2, 344 students completed the pre-travel questionnaire and 172 students completed the post-travel questionnaire. Approximately 3 out of 4 respondents were women (which closely mirrors the $72 \%$ female participation in all programs), and the majority rated their health as very good or excellent. Most respondents were juniors or seniors in college. Respondents represented all 7 academic colleges at the University on both the pre- and post-questionnaires. Representation based on the percent of enrolled

Table 2. Characteristics of college students who completed pre- and post-travel questionnaires.

\begin{tabular}{|c|c|c|}
\hline \multirow[b]{2}{*}{ Characteristic } & \multicolumn{2}{|c|}{ Questionnaires } \\
\hline & Pre $N=344$ & Post $N=172$ \\
\hline \multicolumn{3}{|l|}{ Sex } \\
\hline Women, \% & 76 & 78 \\
\hline \multicolumn{3}{|l|}{ Self-Rated Health } \\
\hline Poor or Fair, \% & 6 & 13 \\
\hline Neutral, \% & 18 & 19 \\
\hline Very Good or Excellent, \% & 76 & 67 \\
\hline \multicolumn{3}{|l|}{ Class Status } \\
\hline Freshmen, \% & 4 & 2 \\
\hline Sophomore, \% & 26 & 23 \\
\hline Junior, \% & 39 & 40 \\
\hline Senior, \% & 31 & 35 \\
\hline \multicolumn{3}{|l|}{ College Affiliation } \\
\hline Agriculture \& Natural Resources, \% & 6 & 4 \\
\hline Arts and Sciences, \% & 40 & 40 \\
\hline Business \& Economics, \% & 26 & 26 \\
\hline Earth, Ocean, \& Environment, \% & 5 & 6 \\
\hline Education \& Human Development, \% & 5 & 5 \\
\hline Engineering, \% & 8 & 9 \\
\hline Health Sciences, \% & 14 & 16 \\
\hline
\end{tabular}


students in a program who completed these questionnaires was similar. Students from the College of Arts and Sciences represented $40 \%$ of the respondents, followed by Business and Economics with 26\%, and then Health Sciences with 14\% - 16\%. Students from each of the 55 travel study programs completed the pre-questionnaire. The mean pre-questionnaire response rate per program was $29.4 \%$, with a range of $10 \%$ to $75 \%$. However, students from only 45 programs completed the post-questionnaire with a mean response rate of $10.6 \%$ and a range of $3 \%$ to $30 \%$.

\subsection{Health-Related Topics}

In the pre-travel questionnaire students were asked to rank the importance of 10 factors that, in their opinion, impact optimal health. All these factors were included in the e-magazine (Table 1). As shown in Table 3, dietary habits were ranked as the most important topic and alcohol consumption as the least important. Students were also given the opportunity to list their own areas of importance, and a few respondents noted mental health and stress management.

After completion of the travel study, students were asked to indicate which topics from the e-magazine they used during their program. Information on hydration, health during travel, and getting enough sleep were the 3 topics most frequently reported, while fitness was the least utilized (Table 3). Nineteen percent reported that they would have concerns about maintaining their health if they enrolled in another travel study program (Table 4). Eighty-seven percent of the respondents indicated that they would recommend How to Stay Healthy While Studying Abroad to others who are going on a travel study program, and $76 \%$ thought the guide should also be recommended to others who are on living on campus.

Table 3. Ranking of physical wellness components by college students enrolled in travel study programs.

\begin{tabular}{ccc}
\hline Pre-travel questionnaire & \multicolumn{2}{c}{ Post-travel questionnaire } \\
\hline Topics considered important $^{\mathrm{a}}$ & $E$-magazine topic & \% $^{\mathrm{b}}$ \\
\hline Dietary habits & Hydration & 66 \\
Hydration & Health during travel & 57 \\
Getting enough sleep & Getting enough sleep & 54 \\
Physical activity & Sun safety & 51 \\
Time management & Time management & 50 \\
Fitness & Physical activity & 44 \\
Snacking & Dietary habits & 39 \\
Health during travel & Alcohol consumption & 38 \\
Sun safety & Snacking & 29 \\
Alcohol consumption & Fitness & 16 \\
\hline
\end{tabular}

a. Topics listed from highest to lowest priority based on student response $(n=344)$. b. Percentage of students who used $e$-magazine topic during travel study program $(\mathrm{n}=172)$. 
Table 4. Health-related attitudes and perceptions of college students enrolled in travel study.

\begin{tabular}{|c|c|c|c|c|c|}
\hline Statement & 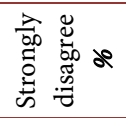 & 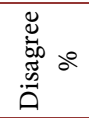 & $\begin{array}{l}\dot{\Xi} \\
\stackrel{ \pm}{ \pm} \\
z\end{array}$ &  & 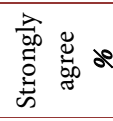 \\
\hline \multicolumn{6}{|l|}{ Pre-travel attitudes ${ }^{2}$} \\
\hline I will never be here again, it doesn't matter what I eat & 13 & 37 & 28 & 19 & 3 \\
\hline I think I will be able to engage in healthful nutrition habits during travel study & 1 & 8 & 17 & 65 & 9 \\
\hline I will never be here again, it does not matter how much I am physically active. & 13 & 41 & 29 & 15 & 2 \\
\hline I think I will be able to engage in healthful physical activity during travel study & 0 & 7 & 22 & 61 & 10 \\
\hline \multicolumn{6}{|l|}{ Post-travel perceptions ${ }^{b}$} \\
\hline Able to find foods that matched my preferences & 4 & 7 & 14 & 50 & 26 \\
\hline Challenge to engaged in healthful eating habits during travel study & 3 & 14 & 32 & 43 & 9 \\
\hline Challenge to engage in healthful physical activity during travel & 6 & 12 & 30 & 45 & 7 \\
\hline Challenge to get enough sleep during travel & 4 & 26 & 29 & 28 & 14 \\
\hline Concerns about maintaining my health if engage in another travel study & 20 & 34 & 27 & 18 & 1 \\
\hline
\end{tabular}

a. Pre-travel: $\mathrm{n}=344$. b. Post-travel: $\mathrm{n}=172$.

\subsection{Attitudes, Perceptions, and Behaviors: Diet, Hydration, and Alcohol Consumption}

On the pre-travel questionnaire $40 \%$ of students indicated that it did matter what foods they ate during travel, while $22 \%$ felt it did not matter (Table 4 ). The majority (74\%) felt they would be able to engage in healthful eating, while $9 \%$ thought they would not. Yet on the post-questionnaire, 52\% reported that it was in fact a challenge to eat healthfully. It should be noted that $98 \%$ of respondents were able to correctly identify a healthful meal and 99\%, an unhealthful meal. Three out of 4 (76\%) students were able to find foods that matched their eating preferences. The majority of students (81\%) indicated that they were self-motivated to eat a healthful diet, while $36 \%$ indicated that their peers encouraged them to eat healthfully. The guide was among the top 3 motivators being cited by $12 \%$ of the students. Other factors which influenced healthful eating were host families and the host culture.

Students reported their water consumption pre- and post-travel. The percentage of students who reported $\leq 1 \mathrm{~L}$ per day (d) increased from $10 \%$ to $14 \%$, and between $2-3$ $\mathrm{L} / \mathrm{d}$ from $29 \%$ to $34 \%$ while the percentage that reported consumption of $1-2 \mathrm{~L} / \mathrm{d}$ decreased from $29 \%$ to $23 \%$. There were no differences between 3 - $4 \mathrm{~L} / \mathrm{d}$.

On the pre-travel questionnaire $34 \%$ of participants reported that they thought their alcohol consumption would increase during their travel study program by $1-4$ drinks a day while 54\% reported that they did not expect any changes. In the post-travel questionnaire, $36 \%$ of participants reported that they had a $1-4$ drink increase in alcohol consumption while $41 \%$ reported no changes in their alcohol consumption.

\subsection{Attitudes, Perceptions, and Behaviors: Activity, Sleep, and Time Management}

Over half (54\%) of the students felt that being physically active while traveling mat- 
tered, and $71 \%$ felt they could engage in physical activity while traveling (Table 4). Prior to traveling, $70 \%$ of respondents indicated that they engaged in vigorous activity, and $84 \%$ engaged in moderate intensity physical activity weekly. Although the percentage of respondents engaging in vigorous activity decreased to 54\% during travel, the percentage of respondents engaging in moderate intensity physical activity remained the same (84\%). In the post-travel questionnaire, $52 \%$ of respondents indicated that it was a challenge to engage in physical activity while traveling. Similarly to engaging in healthful eating, being self-motivated was a factor reported by $81 \%$ of respondents to encourage being physically active. However, $51 \%$ of respondents indicated that peers were influential in their being physically active, and $5 \%$ of respondents noted the guide offered encouragement.

In the pre-travel questionnaire, most students reported getting 7 to 9 hours of sleep per night during the week (48\% Sunday through Wednesday nights, 53\% Thursday through Saturday nights). Approximately $20 \%$ of students indicated less than 6 hours of sleep per night during the entire week. The remainder reported 6 to 7 hours of sleep. In the post-travel questionnaire $42 \%$ indicated it was a challenge to get adequate sleep (Table 4). The time spent sleeping on Sunday through Wednesday nights was less than 6 hours per night for $22 \%$ of respondents, 6 up to 7 hours for $37 \%$ of respondents, and 7 up to 9 hours for $40 \%$ of respondents. Less sleep was reported on Thursday to Saturday nights (35\% had $<6$ hours, 30\%, 6 up to 7 hours, and $36 \%$ had 7 up to 9 hours).

Most students perceived that they possessed very effective (17\%) or somewhat effective (50\%) time management skills on the pre-travel questionnaire. Only $1 \%$ indicated that they do not manage time effectively, while $17 \%$ noted they struggled to manage time effectively. The remaining $14 \%$ selected neutral as their pre-departure response to this question. In contrast, only $7 \%$ stated neutral with respect to time management during travel while $12 \%$ said they struggled to manage time more effectively. In the post-travel questionnaire, 33\% responded that they managed time effectively and $48 \%$ somewhat effectively.

\subsection{Barriers}

Over half $(52 \%)$ of the respondents indicated that it was more challenging to eat a healthful diet and to engage in physical activity while on travel study compared to being on-campus (Table 4). The top 3 barriers to consuming a healthful diet were lack of healthful food, choosing not to eat healthfully, and lack of preferred food. Approximately 1 in 4 students indicated that they were not encouraged to eat healthfully because there was a lack of people around them who ate healthfully (Table 5). Other reasons mentioned were lack of self-motivation, that the cultural norms did not permit small portions, that a combination of healthful and unhealthful foods were consumed, and that overeating occurred because of enthusiasm to try new foods.

The top 2 barriers reported by students which discouraged them to participate in physical activity included choosing to spend time doing other activities and lack of appropriate facilities to engage in such activities. The next 3 most frequently barriers 
Table 5. Perceived barriers to engaging in healthy lifestyle behaviors reported by college students enrolled in travel study.

\begin{tabular}{ll}
\hline Perceived Barrier & Response \% \\
\hline Healthful Eating & 37 \\
Lack of healthful food & 37 \\
Choosing not to eat healthfully & 34 \\
Lack of preferred food & 26 \\
Lack of people around them who ate healthfully & 19 \\
Lack of self-motivation & $<1$ \\
Cultural norms did not permit small portions & $<1$ \\
Consumed both healthful and unhealthful foods & $<1$ \\
Overate due to enthusiasm to try new foods & \\
Physical Activity & 56 \\
Choosing to spend time doing other activities & 56 \\
Lack of appropriate facilities & 41 \\
Not having enough time & 16 \\
Lack of self-motivation & 25 \\
Lack of safe area to exercise & 21 \\
Weather not conducive & 19 \\
Choosing not to be physically active & \\
\hline Lack of people with whom to exercise & \\
\hline
\end{tabular}

a. Post-travel: $\mathrm{n}=172$.

mentioned were not having enough time, lack of self-motivation, and lack of safe area to exercise. Other barriers reported by less than $20 \%$ of respondents included weather not conducive, choosing not to be physically active, and lack of people with whom to exercise (Table 5).

\section{Discussion}

To our knowledge, How to Stay Healthy While Studying Abroad is the first electronic comprehensive physical wellness guide designed for travel study students. Furthermore, we believe this is the first study that evaluated the attitudes, perceptions, behaviors, and barriers related to wellness of college undergraduates enrolled in a travel study program. These data revealed the e-magazine content was on target and that this guide is needed since achieving wellness during travel was sometimes more challenging than expected. As evidenced by our findings the sections on hydration, health during travel, and getting enough sleep were the most utilized by students. The reported decrease in water consumption and hours slept during travel suggest the need to emphasize these topics, possibly integrating these topics throughout the guide. Fatigue associated with dehydration and lack of sleep can impact an individual's selection of foods to eat, mo- 
tivation to be physically active, and time management skills. Fitness was reported as the least utilized section from the guide. This result was unexpected since the guide provided exercises that could be done in a room if outdoor safe areas could not be identified.

Lack of self-motivation/choosing to not be healthful and lack of social support were barriers to both eating healthfully and engaging in physical activity. To improve future editions of How to Stay Healthy While Studying Abroad, several changes can be made to address these barriers. For instance, to help students strengthen their social support system, a section can be added describing how students can facilitate conversations with others to foster positive social support around physical wellness. Students can be encouraged to be physically active together and to explore safe areas of their host site with their peers. Students may be more motivated to eat healthfully if they are provided guidance on how to plan ahead to identify and locate restaurants, local markets and/or groceries that offer a variety of foods that match their preferences. Similar to the initial development of the guide, focus groups with college students could be conducted to determine what additional information would be most useful.

Some students reported that their alcohol consumption increased by $1-4$ drinks a day during their travel study programs, which supports Bonner's (2001) finding that drinking increases when individuals study abroad. Students can and should be encouraged to abstain or drink wisely and in moderation while exploring their new environment to minimize detrimental aspects of drinking in an unfamiliar environment. Perhaps more emphasis could be placed on quality versus quantity drinking with the addition of how to taste wines and other alcoholic beverages and providing a wine flavor wheel.

Most students reported they would recommend How to Stay Healthy While Studying Abroad to others who are studying abroad, as well as to students who are living on campus. This could imply that students felt confident that the guide might help others, and even foster positive health behaviors while on campus. This finding supports the inclusion of physical wellness guides in pre-departure material for students enrolled in a travel study program. Further, this guide proved effective because over half of students reported that they would not have concerns about maintaining their health if they enrolled in another travel study program. Only a minority of students (19\%) felt they would have concerns maintaining their health on another study abroad. A possible explanation may be that their destination countries may be vastly different from each other, offering varying possibilities to maintain optimal wellness. To enhance comfort level with traveling, additional links to country/regional resources could be added to the guide.

There were several limitations to this study. Students in the pilot survey group had increased nutrition and physical activity knowledge based on their college major, which could have skewed the results and which topics were emphasized in the guide. The study group surveyed was a convenience, non-random sample. Students volunteered to participate and therefore may have been more concerned with their physical wellness 
than the larger population of study abroad participants. If the guide were included in mandatory pre-departure materials, and the post-questionnaire required, a larger more representative sample of students from all colleges could be used to evaluate effectiveness of the guide. Although the e-magazine format was aesthetic, internet access was needed to view the guide. Students with no/poor internet access could not view the guide. In the future, alternative options, such as a print version or text messaging, to access How to be Healthy While Studying Abroad could be offered. Exploration of text messaging has been shown effective for smoking cessation programs with college students (Obermayer, Riley, Asif, \& Jean-Mary, 2004) and perhaps might be beneficial in helping students overcome technical barriers during their travel study program.

\section{Conclusion}

In conclusion, the e-magazine How to Be Healthy While Studying Abroad was utilized by students to maintain their physical wellness during travel study programs. Editing content to address barriers in an encouraging and positive matter and introducing other forms of media to distribute this guide may enable more students to become knowledgeable of the skills which are necessary to maintain physical wellness, not only while on a travel study program but also throughout life.

\section{References}

Anderson, P., Lawton, L., Rexeisen, R., \& Hubbard, A. (2006). Short-Term Study Abroad and Intercultural Sensitivity: A Pilot Study. International Journal of Intercultural Relations, 30, 457469. http://dx.doi.org/10.1016/j.ijintrel.2005.10.004

Bonner, J. M. (2001). Risky Business: Student Behavior Abroad. Transitions Abroad. http://www.transitionsabroad.com/publications/magazine/0105/bonner.shtml

Chieffo, L., \& Griffiths, L. (2004). Large-Scale Assessment of Student Attitudes after Short Term Study Abroad Program. Frontiers: The Interdisciplinary Journal of Study Abroad, 10, 165-177.

Clarke, I., Flaherty, T., Wright, N., \& McMillen, R. (2009). Student Intercultural Proficiency from Study Abroad Programs. Journal of Marketing Education, 31, 173-181. http://dx.doi.org/10.1177/0273475309335583

Corbin, C. B., \& Pangrazi, R. P. (2001). Toward a Uniform Definition of Wellness: A Commentary. President's Council on Physical Fitness and Sports Research Digest, Series 3, \#15, 1-3.

Czerwionka, L., Artamonova, T., \& Barbosa, M. (2015). Intercultural Knowledge Development: Evidence from Student Interviews during Short-Term Study Abroad. International Journal of Intercultural Relations, 49, 80-99. http://dx.doi.org/10.1016/j.ijintrel.2015.06.012

Douglas, C., \& Jones-Rikkers, C. (2001). Study Abroad Programs and American Student Worldmindedness. Journal of Teaching in International Business, 13, 55-66. http://dx.doi.org/10.1300/J066v13n01 04

Dwyer, M. M., \& Peters, C. K. (2004). The Benefits of Study Abroad. IES Abroad News. http://www.iesabroad.org/study-abroad/news/benefits-study-abroad\#sthash.r4o2pfPo.dpbs

Gambino, G., \& Mohsin Hashim, S. (2016). In Their Own Words: Assessing Global Citizenship in a Short-Term Study-Abroad Program in Bangladesh. Journal of Political Science Education 12, 15-28. http://dx.doi.org/10.1080/15512169.2015.1063438

Hartjes, L. B., Baumann, L. C., \& Henriques, J. B. (2009). Travel Health Risk Perceptions and 
Prevention Behaviors of US Study Abroad Students. Journal of Travel Medicine, 16, 338-343. http://dx.doi.org/10.1111/j.1708-8305.2009.00322.x

Institute for Global Studies Travel Study Handbook (2015).

http://www1.udel.edu/global/studyabroad/documents/travelstudyhandbook.pdf

Institute of International Education (2015). Leading Institutions by Study Abroad Total, 2013/14. Open Doors Report on International Educational Exchange. http://www.iie.org/opendoors

Interorganizational Task Force on Safety \& Responsibility in Study Abroad (2002). Responsible Study Abroad: Good Practices for Health \& Safety.

http://www.nafsa.org/uploadedFiles/responsible study abroad.pdf

JED Foundation, \& Settle, W. (2008). Depression and Suicidal Behaviors in Students Studying Abroad.

https://www.jedfoundation.org/assets/Programs/Program downloads/StudyAbroad documen t.pdf

Kitsantas, A. (2004). Studying Abroad: The Role of College Students' Goals on the Development of Cross-Cultural Skills and Global Understanding. College Student Journal, 38, 441-452.

Norris, M., \& Gillespie, J. (2008). How Study Abroad Shapes Global Careers: Evidence from the United States. Journal of Studies in International Education, 13, 382-397.

http://dx.doi.org/10.1177/1028315308319740

National Health and Nutrition Examination Survey (2008). Physical Activity and Physical Fitness - PAQ. https://www.cdc.gov/nchs/data/nhanes/nhanes 07 08/mi paq_e.pdf

Obermayer, J. L., Riley, W. T., Asif, O., \& Jean-Mary, J. (2004). College Smoking-Cessation Using Cell Phone Text Messaging. Journal of American College Health, 53, 71-78. http://dx.doi.org/10.3200/JACH.53.2.71-78

Rogers, H. L., \& Reilly, S. M. (2000). Health Problems Associated with International Business Travel. A Critical Review of the Literature. American Association of Occupational Health Nurses Journal, 48, 376-384.

Stebleton, M., Soria, K., \& Cherney, B. (2013). The High Impact of Education Abroad: College Students' Engagement in International Experiences and the Development of Intercultural Competencies. Frontiers: The Interdisciplinary Journal of Study Abroad, 22, 1-25.

Stewart, L., \& Leggat, P. A. (1998). Culture Shock and Travelers. Journal of Travel Medicine, 5, 84-88. http://dx.doi.org/10.1111/j.1708-8305.1998.tb00469.x

Submit or recommend next manuscript to SCIRP and we will provide best service for you:

Accepting pre-submission inquiries through Email, Facebook, LinkedIn, Twitter, etc.

A wide selection of journals (inclusive of 9 subjects, more than 200 journals)

Providing 24-hour high-quality service

User-friendly online submission system

Fair and swift peer-review system

Efficient typesetting and proofreading procedure

Display of the result of downloads and visits, as well as the number of cited articles

Maximum dissemination of your research work

Submit your manuscript at: http://papersubmission.scirp.org/ 